\title{
Laryngeal trauma: A diagnostic case study ${ }^{*}$
}

\author{
Loren B Schneider BA (Sp \& H Therapy) (Witwatersrand) \\ Baragwanath Hospital, Johannesburg \\ Anthony Traill PhD (Witwatersrand) \\ Department of Linguistics \\ University of the Witwatersrand, Johannesburg \\ Lesley Wolk MA (Speech Pathology) (Witwatersrand) \\ Department of Speech Pathology and Audiology, \\ University of the Witwatersrand, Johannesburg
}

\begin{abstract}
This study investigates the physiological mechanism responsible for reappearance of phonation in an aphonic subject with traumatic laryngeal damage. The battery of procedures involved spectrography, laryngographic analysis, fiberoptic laryngoscopy, tomography, lateral xerography and cinefluorography. Results show that the subject's abnormal laryngeal anatomy facilitated a novel adductory mechanism for vocal fold vibration involving a type of sphincteric constriction between the arytenoid cartilages and the epiglottis. The value of a battery of diagnostic measures is highlighted.
\end{abstract}

\section{OPSOMMING}

Hierdie studie ondersoek die fisiologiese meganisme wat verantwoordelik is vir die herverskyning van fonasie in 'n afonie geval met troumatiese laryngeale beskadiging. Die ondersoek battery het spektrografie, laringografiese analise, fiberoptiese laringoskopie, tomografie, laterale xerografie en cinefluorografie ingesluit. Resultate dui daarop dat die proefpersoon se abnormale larinks-anatomie 'n ongewone adduksie meganisme bewerkstellig het vir die stemband vibrasie, naamlik, 'n sfinkter vernouing tussen die aritenoide kraakbene en die epiglottis. Die waarde van 'n metingsbattery vir diagnose word uitgelig.

Laryngeal injury was prevalent during the two World Wars (Luchsinger and Arnold, 1965). Post-war, the incidence decreased. Today, we are again witnessing an acceleration of laryngeal injuries. This has been attributed to the sustained increase in motor vehicle accidents and rise in violent crimes, an inexorable fact of our present society (Luchsinger and Arnold, 1965). Most interest in laryngeal trauma has been confined to medical literature. There is a paucity of research on laryngeal injury with regard to vocal rehabilitation by the speech clinician.

A detailed investigation of recent literature reveals only one study viewing laryngeal trauma in relation to voice therapy (Mitrinowicz-Modrzejewska, 1962). In this study, two cases of laryngeal trauma are discussed, and it is concluded that voice therapy is possible, even under highly adverse circumstances and following long periods of post-traumatic aphonia. However, differential diagnosis is essential before any treatment is undertaken. Trauma results in disorders of variable type and degree, ranging from slight dysphonia to complete aphonia. The nature of the laryngeal damage must be determined, as treatment and prognosis will depend on the site and extent 'of structural involvement.

Different perspectives on subjective and objective measures have been highlighted in the literature. It is apparent that earlier clinicians were more dependent on subjective measures, whereas later writers have attempted to objectify evaluation. Kelman, Gordon, Morton and Simpson (1981) attribute this to the recent advent of electronic instruments for assessment of vocal behaviour. The advantages of the various objective measures have been emphasized by many writers. The inaccessibility of the phonatory mechanism renders fiberoptic and radiological techniques invaluable in diagnostic evaluation. For acoustic analyses of the speech waveform, writers have stressed the value of spectrography (Kerr and Lanham, 1973; Rontal, Rontal and Rolnick, .1975) and laryngography (Fourcin, 1974). A combination of subjective and objective evaluation is still felt to be optimal (Aronson, 1980, p. 171). The major aim of this study was thus to use a multidimensional approach in an in-depth evaluation of the structural and functional components responsible for phonation in a case with laryngeal damage due to trauma.

\section{METHOD}

\section{SUBJECT}

The subject, M.P., is an English-speaking adult male, aged 24 years, who suffered a motorcycle accident in which his larynx was crushed by a wire stretched across the road.

Summaries of the pertinent post-traumatic medicai events are presented in Table 1.

* This article is based upon the first ,author's research report entitled "Laryngeal trauma: A diagnostic case study" submitted to the Department of Speech Pathology \& Audiology, University of the Witwatersrand, Johannesburg. 
Table 1 Summary of post-traumatic medical events

\begin{tabular}{|c|c|c|c|}
\hline DATE & EVENT. & DESCRIPTION OF FINDINGS & $\begin{array}{l}\text { VOCAL } \\
\text { HISTORY }\end{array}$ \\
\hline 15.01 .78 & Motorcycle acciüeiti & $\begin{array}{l}\text { Crushed tracheal cartilages and } \\
\text { severe damage to larynx }\end{array}$ & $\begin{array}{l}\text { Post-Traumatic } \\
\text { Aphonia }\end{array}$ \\
\hline 30.01 .78 & $\begin{array}{l}\text { Tracheostomy; Graft inserted } \\
\text { around trachea }\end{array}$ & & \\
\hline 28.04 .78 & $\begin{array}{l}\text { Direct laryngoscopy; } \\
\text { Bronchoscopy; } \\
\text { tracheal dilation }\end{array}$ & $\begin{array}{l}\text { Left vocal fold moved poorly; } \\
\text { Right vocal fold normal; } \\
\text { Marked fibrosis and stenosis }\end{array}$ & \\
\hline 07.05 .78 & Subglottal T-tube insertion & $\begin{array}{l}\text { Vocal cords immobile; } \\
\text { Ventricular cords moving }\end{array}$ & \\
\hline 08.01 .79 & $\begin{array}{l}\text { Removal of T-tube; } \\
\text { Direct laryngoscopy }\end{array}$ & $\begin{array}{l}\text { Vocal cords scarred and } \\
\text { immobile; Ventricular cords } \\
\text { moving }\end{array}$ & \\
\hline 01.05 .79 & $\begin{array}{l}\text { Direct laryngoscopy; } \\
\text { Granuloma removal }\end{array}$ & $\begin{array}{l}\text { Vocal cords immobile; } \\
\text { Very narrow trachea }\end{array}$ & $\begin{array}{l}\text { Voice therapy } \\
\text { received. }\end{array}$ \\
\hline 07.09 .81 & $\begin{array}{l}\text { Direct laryngoscopy: } \\
\text { Laser therapy (for anterior } \\
\text { web and subglottal scarring) }\end{array}$ & $\begin{array}{l}\text { Vocal cords not moving normally; } \\
\text { Scarring of left vocal cord }\end{array}$ & $\begin{array}{l}\text { resulting in low- } \\
\text { pitched, severely } \\
\text { hoarse phonation }\end{array}$ \\
\hline 12.11 .82 & $\begin{array}{l}\text { Dirent lenyngoscupy; } \\
\text { Laser therapy }\end{array}$ & $\begin{array}{l}\text { Oedematous vocal cords; } \\
\text { Some movement detected; } \\
\text { Ventricular cord closure; No web }\end{array}$ & $\begin{array}{l}\text { Referred for } \\
\text { further } \\
\text { voice therapy. }\end{array}$ \\
\hline
\end{tabular}

The vocal history is as follows: In January 1979 M.P. presented with post-traumatic aphonia. Between March and October of that year he received voice therapy resulting in low-pitched, severely hoarse phonation. He reported a gradual improvement in voice quality over the next three years. After the medical examination and laser therapy in November 1982 he wàs referred for further voice therapy. At this stage it was suggested that nerve re-generation may have occurred to explain mövement observed in the vocal cords (See Table 1).

\section{PROCEDURE}

\section{Preliminary Measures}

Audiometric evaluation revealed hearing within normal limits bilaterally. Oral peripheral examination revealed structural and functional adequacy of the oral peripheral mechanism ifor speech.

\section{Voice evaluation}

\section{A. Subjective evaluation}

A voice sample was recorded including connected speech, reading, selected speech sounds and cöünting at värying rates, loudness and pitch levels. Aspects of respiration, phonation and resonance were analysed descriptively. A voice scale was completed in an attempt to confirm and objectify subjective evaluation. The Buffalo Voice Profile (Wilson, 1979) was selected for evaluation of vocal parameters as a baseline measure and was judged by two qualified speech therapists. The judges were naive as to the aims of the study and had had no previous contact with the subject.

\section{B. Objective evaluation}

\section{INDIRECT LARYNGOSCOPY}

Indirect laryngoscopy was carried out by an ENT specialist following the procedure of mirror laryngoscopy.

\section{SPECTROGRAPHY}

Spectrographic analysis was performed on a Kay Sonagraph Model 6061-B. Broad and narrowband spectrograms weire made as well as sections. The vowels [a: ] and [i:] wore used for analysis and sentences were used to supplement this data.

\section{FIBEROPTIC EXAMINATION}

The flexible fiberoptic laryngoscope provides a means of visualising and identifying normal or abnormal laryngeal structure and regulation during voice production. A ronson (1980) states that this is the only assessment technique which allows observation of the vocal folds during connected speech. Fiberoptic exanîination was carried out, using a flexible fiberoptic nasolärỹugòscope Olympus Type VF4A. Several slides were takên of the lärynx düring quiet respira'tion and sustained vowielel production. Phonation was! tape recorded concurrently, tallowing for corrèlation of slides with corresponding utterances.

\section{LARYNGOGRAPHY}

The laryngograph is "an electrical impedance technique ... for the direct examination of vocal fold closure, which does not "initerfere with phonation" (Fourcin, 1974). The laryngographic procedure described by Wechsler (1977), was carried out, using the Fourcin Laryngograph and Voicescope. 
M.P. was required to produce sustained phonation on the vowels [a:] and [i:] during level and rising pitches. A sentence was recorded to supplement the data. The output of the Laryngograph and Voicescope was simultaneously recorded on a Mingògraf inkjet recorder.

\section{FRONTAL TOMOGRAPHY AND LATERAL XEROGRAPHY}

Many writers advocate the use of X-ray techniques in the diagnosis of voice disorders, for example, Fletcher, Shelton, Smith and Bosma (1960), who stress the need for research in this area. In traumatic cases, radiological measures aid in determining the extent of structural damage. For an anteroposterior view of the larynx, frontal tomograms were taken. For a lateral view of the larynx, lateral xerography was carried out. Tomograms and xerograms were taken at rest and during sustained phonation. The audio signal was tape recorded to ensure that the exposure had coincided with phonation and for later spectrographic analysis.

\section{CINEFLUOROGRAPHY}

Cinefluorography is a technique using "electronic image intensification, in which motion pictures are taken from a fluoroscopic screen" (Moll, 1960). One of the major advantages of this technique is in its application to the dynamics of connected speech. This allows the study of movement, rather than a single pose taken at one instant in time. A barium compound was introduced through the subject's nostrils into the pharynx to add clarity to the image, and he produced a few seconds of spontaneous speech and sustained vowel phonation to determine the exact locus and nature of his vibratory source.

\section{RESULTS}

\section{SUBJECTIVE EVALUATION}

Table 2 represents a summary of the parameters evaluated qualitatively by the investigators, from a recorded speech sample, and includes findings from the rated Buffalo Voice Profiles.

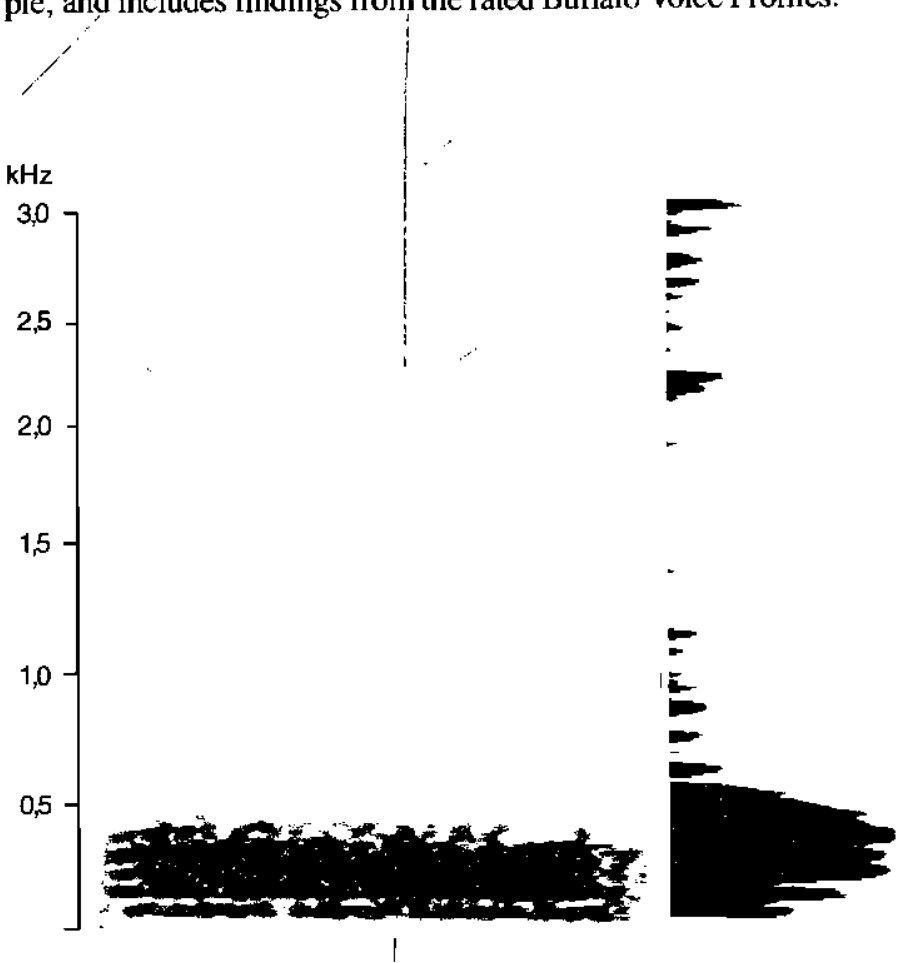

Table 2 Summary of findings of subjective voice analysis

\begin{tabular}{|c|c|}
\hline Respiration & $\begin{array}{l}\text { Thoracic type of breathing; restricted capacity; } \\
\text { poor respiratory control, as assessed through } \\
\text { phono-respiratory tasks extracted from Boone } \\
(1977, \text { p. } 85)\end{array}$ \\
\hline Loudness & $\begin{array}{l}\text { Adequate volume in habitual phonation, but pro- } \\
\text { gressive decrease in loudness during sustain- } \\
\text { ed vowel production, which could be related to } \\
\text { inadequate respiratory function }\end{array}$ \\
\hline Pitch & $\begin{array}{l}\text { Low habitual and optimum pitch levels; limited } \\
\text { pitch range; no pitch breaks. }\end{array}$ \\
\hline Quality & Hoarse; breathy; auditorily rough; diplophonic \\
\hline Steadiness & $\begin{array}{l}\text { Steady at habitual pitch level; unsteady when re- } \\
\text { quired to raise pitch level, possibly attributable } \\
\text { to excessive tension. }\end{array}$ \\
\hline Rate & $\begin{array}{l}\text { Within normal limits, confirmed by raters Wilson, } \\
1979, \text { p. } 88 \text { ) }\end{array}$ \\
\hline Resonance & $\begin{array}{l}\text { Within expected range, confirmed by raters } \\
\text { (Boone, 1977, p. 98) }\end{array}$ \\
\hline $\begin{array}{l}\text { Overall vocal } \\
\text { efficiency }\end{array}$ & Moderately impaired \\
\hline
\end{tabular}

\section{OBJECTIVE EVALUATION}

\section{A. Indirect laryngoscopy}

Examination during quiet breathing revealed no significant variables in terms of the medical status of M.P.'s laryngeal structures. Assymmetry of the vocal cords was reported, with the left vocal cord situated at a higher level than the right vocal cord. During phonation a posterior movement of the epiglottis obstructed the view of the vocal cords, preventing any observation of their state during phonation.

Figure 1 Narrow band spectrograms and acoustic sections of the sustained vowels [i:] and [a:]. 


\section{B. Spectrographic analysis.}

The broadband and narrowband spectrograms were analysed in terms of the following parameters:

\section{Fundamental frequency}

The fundamental frequency was measured at various places in connected speech. The figures obtained were averaged, yielding a fundamental frequency of $77 \mathrm{~Hz}$. This is well below the norm for males, i.e. $120 \mathrm{~Hz}$. (Fry, 1979).

\section{Harmonic components}

In comparison to a normal spectrogram a relatively restricted range of harmonics was evident. As is illustrated in Figure 1, in some parts of the narrowband spectrograms and on the sections, clear harmonics were evident with a good signal to noise ratio, while in others the signal to noise ratio was poor. Nevertheless, during production of both [a:] and [i:] a sufficiently rich range of harmonics was always evident.

\section{Formant structure}

In normal phonation, the first four formants are usually clear (Kerr and Lanham, 1973). In M.P.'s case, the first three formants were present on most of the wideband spectrograms. However, the higher formants were noise excited. Rontal et al (1975) state that clear formants depend on a lack of breathiness, normal periodicity and a good resonating system. Despite the presence of breathiness and aperiodicity in M.P.'s voice, subjective analysis suggested that the resonatory system was adequate.

\section{Pitch range}

M.P. was able to achieve limited pitch variation of $34 \mathrm{~Hz}$. when asked to produce vowels on a series of pitches, from lowest through to highest.

The highest and second highest pitched vowels he produced had a greater number of clear harmonics than the three lower pitched vowels, indicating that optimal vibratory adjustment occurred at a higher pitch. However, it required additional effort and discomfort for M.P. to raise his pitch to these levels.

\section{Laryngographic analysis}

The parameters analysed were as follows:

1. $L x$ :

Lx provides information concerning the mode of vibration of the vocal folds, and excludes supraglottal information.
The following aspects of $\mathrm{Lx}$ were assessed:

a) Regularity: In the normal larynx, the Lx pattern is regularly repeated, through control of lung air pressure and laryngeal musculature (Abberton, 1972). As can be seen in Figure 2, M.P.'s Lx behaviour was complex and highly irregular throughout the laryngogram. By contrast, the normal Lx waveform represented in Figure 3 is simple and completely regular, indicating a stable vibratory source. M.P.'s Lx tracings exhibit gross cycle to cycle waveform changes, a condition which may bc described (with a little licence) as "Lx shimmer", indicating abnormal vocal fold vibration.

b) Shape: Abberton (1972) describes three phases in the shape of a normal vibratory cycle:

- A rapid closing phase (positive going), i.e. a rise in the waveform associated with the interval of greatest acoustic excitation of the vocal tract.

- A slower opening phase (negative going), i.e. a decline in the waveform associated with the gradual parting of the vocal folds, as the subglottal pressure increases prior to abduction.

- An open phase, i.e. a flat base corresponding to the interval when the vocal folds are out of contact and the glottis is abducted.

The shape of M.P.'s Lx waveform is thoroughly irregular in all these phases. Given the abnormal anatomy of this case it would be unwise to speculate on the precise physiological correlates of the irregularities. However, it may safely be said that the Lx tracings provide clear evidence of variability in the mass, adduction, abduction and probably tension of the vibratory source.

\section{Fx:}

Fx is a display of fundamental frequency. As illustrated in the normal case in Figure 3, Fx takes the form of an even or smoothly varying line. Throughout M.P.'s Fx tracing. an abnormality, termed "jitter", was evident, i.e. small cycle to cycle pitch perturbations due to aperiodicity of the vibratory mechanism. Figure 2 illustrates this. The amount of jitter and shimmer in a signal is directly related to the listener's perceptions of auditory roughness (Wendahl, 1966) and in this case, the large amount of jitter and shimmer corresponded to the rough, hoarse voice quality evident in subjective evaluation.

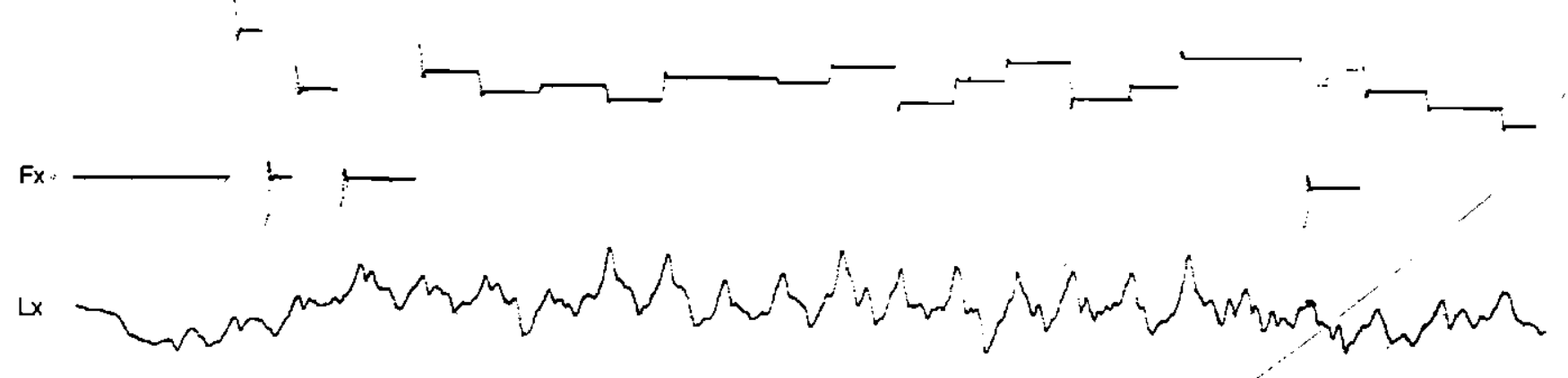

Figure 2 M.P.'s $L x$ and Fx tracings during the production of [i:]. The irregularity of the former would be produced by a highly variable vibratory source. The lack of smoothness of the Fx trace reflects jitter. 
Fx

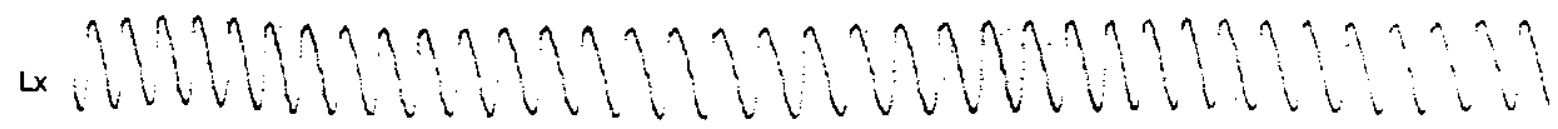

Figure 3 Normal $L x$ waveform of an adult male. The simple and regular Lx trace and the smooth Fx trace contrast with those in Figure 2.
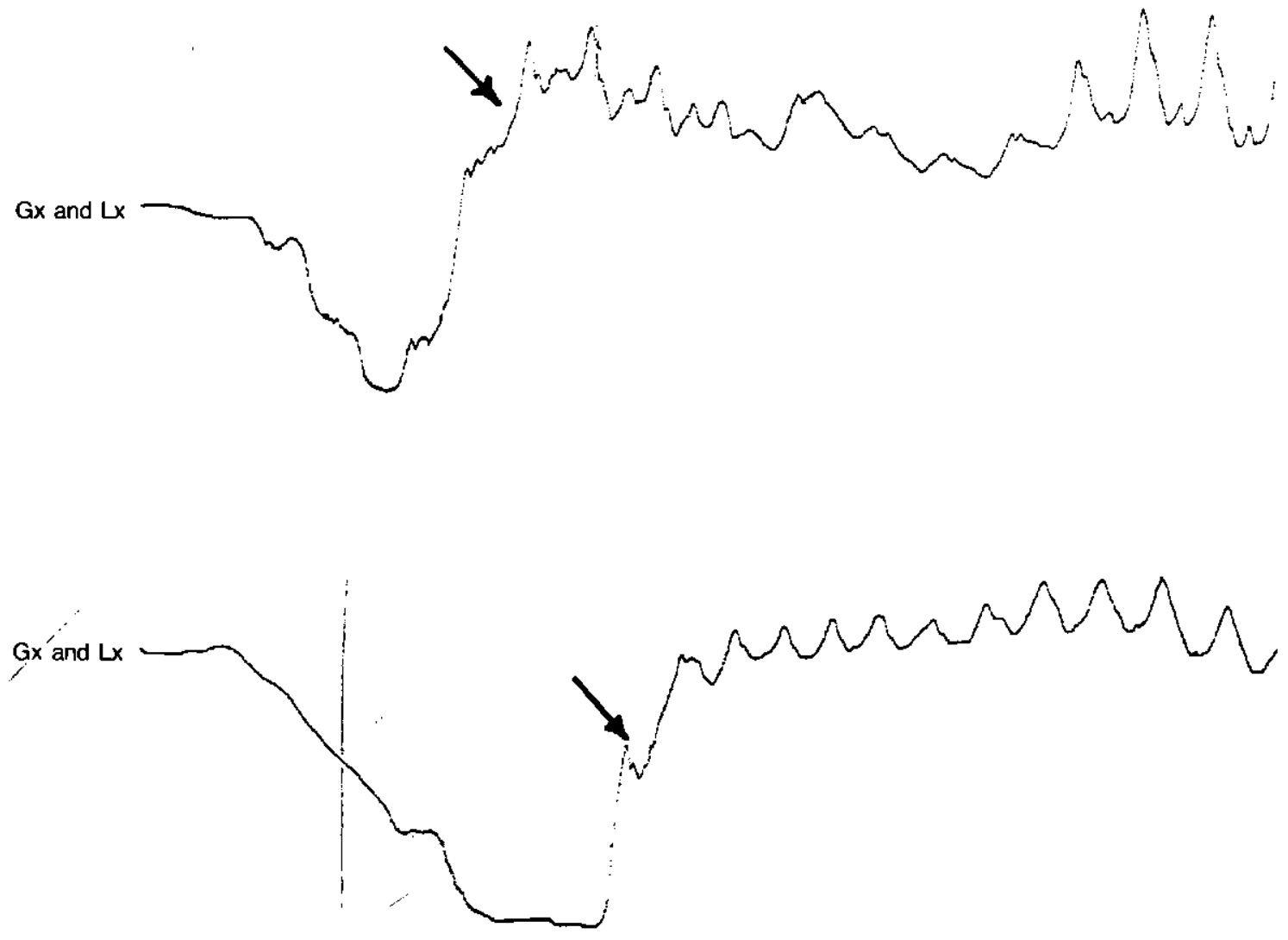

Figure 4 Two Laryngographic tracings illustrating Gx movements frequently observed prior to the onset of phonation (marked with an arrow).

3. $G x$ :

Slower changes on the Lx tracing are termed Gx and they are primarily the result of gross movements of the entire larynx before, during and after phonation, brought about by the function of the extrinsic muscles. Figure 4 illustrates the large Gx movements that were frequently observable prior to the onset of phonation by M.P. Although he does not have a normal laryngeal structure, these Gx movements are precisely what could be expected from the independently observed laryngeal airway adjustments seen during lateral xerography and cinefluorography (see Figure 4).

\section{Fiberoptic analysis}

Slides taken during fiberoptic examination were analysed descriptively at rest and during phonation, in order to determine the structural changes evident during phonation:

\section{At rest}

Figure 5 shows a clear view of one true vocal fold, both ventricular folds, the tips of the arytenoid cartilages and the cushion of the epiglottis. One ventricular fold is larger than the other, approximating the midline and obscuring one true vocal fold. Slight asymmetry of the arytenoid car- 
tilages in relation to each other is evident. During examination, the left arytenoid and vocal fold appeared to be situated at a higher level than the corresponding structures on the right, confirming the findings of indirect laryngoscopy.

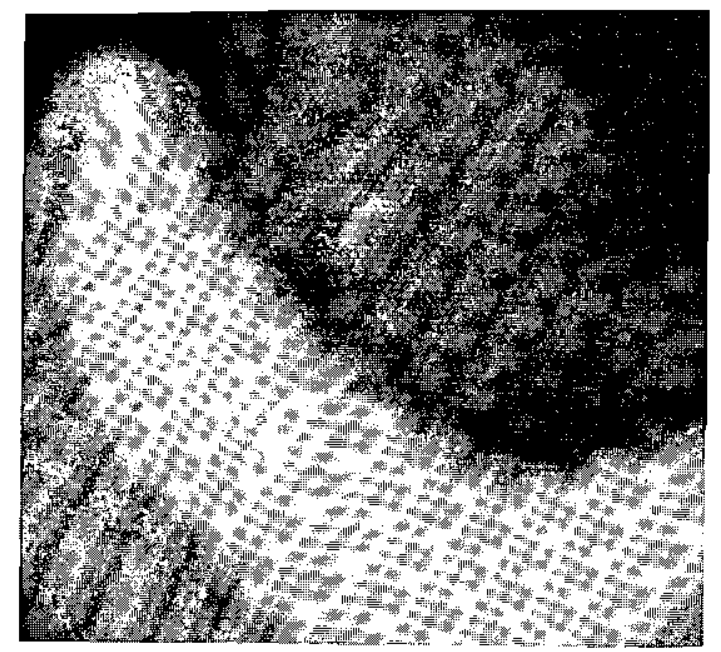

Figure 5 Fiberoptic view of M.P. 's larynx taken at rest. The tips of the arytenoids are visible in the top part of the picture, one true fold and the two ventricular folds in the middle and the cushion of the epiglottis at the bottom centre.

\section{During phonation of [i:]}

It was never possible to view the vocal folds during phonation as the rim of the epiglottis moved posteriorly, obscuring the view of the glottis, as is evident in Figure 6. The posterior aspect of the arytenoids is visible below the epiglottis. During the examination, no vibration of the posterior aspect of the arytenoids was apparent during phonation.

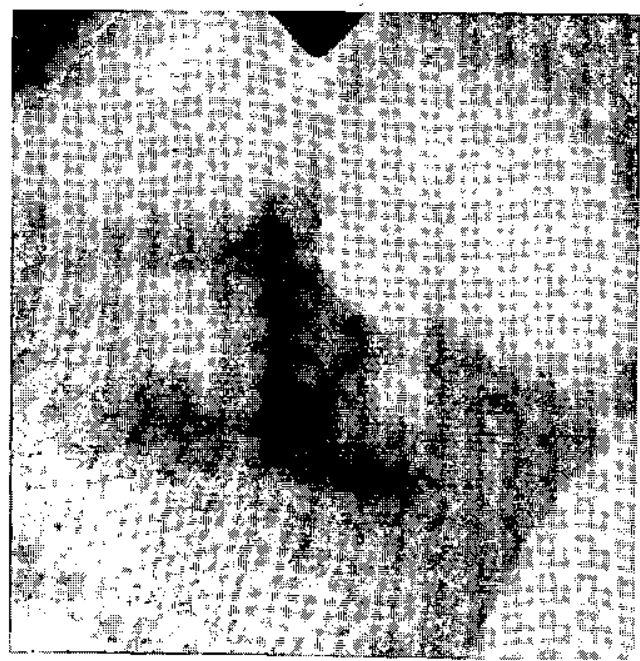

Figure 6 Fiberoptic view of M.P. 's larynx taken during phonation of [i:]. The rim of the epiglottis is visible in the foreground. In the background the posterior aspect of the arytenoid cartilages can be seen. The dark spot at the centre of the picture corresponds to the junction between the arytenoids.

\section{E. Tomography}

Because trauma and surgery had distorted M.P.'s laryngeal structures, conventional landmarks were missing, making it extremely difficult to estimate section depths for the tomograms. Although tomograms were taken at several section depths, clarity did not result and it was not possible to reach any conclusions about the position of the vocal folds during phonation.

\section{F. Lateral xerography}

Xcrograms selected for analysis were those taken at rest and during phonation. Xerograms were analysed using overlay tracings, with bony landmarks as reference points. The cervical vertebrae were used as orientation points by which to align the tracings. In this case conventional grid measures were inapplicable because of the abnormal anatomy, for example, absence of the cricoid and thyroid cartilages. Thus, anatomical changes were analysed descriptively, under the following parameters. selected from a list provided by Berry, Epstein, Fourchin, Freeman, MacCurtain and Noscoe (1982). The reader should consult Figure 7 during the following discussion.

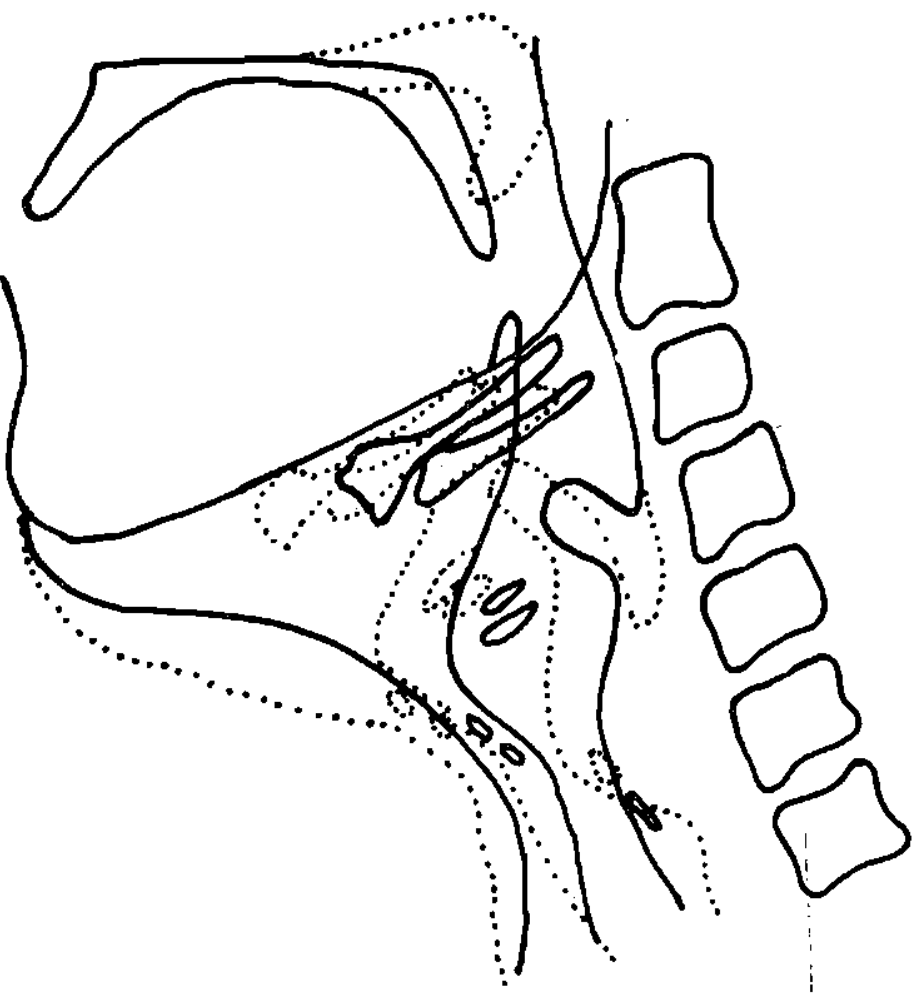

Figure 7 Superimposed tracings taken from xerograms showing structural changes between quiet respiration (solid lines) and phonation (dotted lines) in M.P. 's larynx.

\section{Epiglottis}

One of the major physiological changes evident between quiet respiration and phonation, was a pronounced and $\mathrm{ab}$ normal anterior rotation of the base of the epiglottis and a posterior tilting of its rim. Although the mechanism underlying this movement cannot be stated precisely, it appears to be facilitated by the absence of the thyroid cartilage, which would normally obstruct any anterior movement of the root of the epiglottis.

\section{Hyoid Bone}

During phonation, there was a marked displacement of the hyoid bone anteriorly. Despite this anterior movement, the angle of the hyoid bone is maintained. 


\section{Hypopharynx}

Another major physiological change was an anterior and upward movement of the arytenoid cartilages towards the epiglottis, resulting in a marked expansion of the hypopharynx, both antero-posteriorly and supero-inferiorly.

\section{Vocal folds}

Although the vocal folds were not clearly visible on the lateral xerograms, their presence could be inferred partly from the shape of laryngeal ventricles which were relatively distinct. Two ventricles were visible, one directly above the other, suggesting that the true vocal folds were lying at different heights. This was consistent with superior displacement of the left vocal fold evident during indirect laryngoscopy and fiberoptic examination. During phonation these ventricles were elongated slightly as they moved anteriorly and slightly superiorly in consort with similar movements of the hyoid bone and arytenoid cartilages. It seems reasonable to assume, therefore, that the vocal folds also moved anteriorly and superiorly during adduction.

\section{Dimensions of the laryngeal airway}

Anterior expansion of the entire laryngeal airway was evident during phonation, again in consort with the anterior movement of the other laryngeal structures mentioned. Subglottally, a posterior expansion of the airway was also evident, probably due to air-pressure build-up during phonation. The most interesting physiological change from the rest position to phonation involved the articulation of the arytenoid structure relatively high up on the epiglottis.

It is well known that generalisations about the precise physiology of phonation in connected speech cannot be made from lateral xerography, as this technique provides a static view. Because of this M.P.'s phonatory mechanism was investigated using cinefluorography.

\section{G. Cinefluorography}

The lateral cinefluorographic view of the larynx confirmed the postures evident on the lateral xerograms, i.e. anterior rotation of the base of the epiglottis from a vertical position at rest, through about $45^{\circ}$ during phonation. From lateral xerography it was suspected that vibration between the rotated epiglottis and the arytenoids could have occurred. However, the dynamic image provided by cinefluorography revealed no vibration between these structures.

\section{DISCUSSION}

The result of the xerographic and cinefluorographic investigations revealed that a number of unusual physiological adjustments were involved in M.P.'s phonatory mechanism. These included the extreme tilting of the epiglottis, the prominent expansion of the supra- and subglottic airway and the hypopharynx, and the articulation of the arytenoids relatively high on the broad part of the epiglottis - all undoubtedly due to the subject's abnormal anatomy. In the normal case the base of the epiglottis is attached to the inner aspect of the angle of the thyroid cartilage by the thyro-epiglottic ligament. In M.P.'s case the thyroid cartilage is missing, leaving the base of the epiglottis free to move in the anterior direction seen in Figure 7. This in turn allows for an unusual rotation of the epiglottis relative to the arytenoid cartilages allowing them to articulate high up rather than at the level of the tubercle. The lack of cartilaginous support and the surgically architected airway dimensions are responsible for the expansions in the airway both suband supraglotally.

The position adopted by the epiglottis during phonation prevented any laryngoscopic observation of the vibratory source. This emphasizes the contribution of X-ray techniques. However, it was possible to establish from fiberoptic examination that neither the epiglottis nor the posterior aspects of the arytenoids vibrated during phonation. It should be mentioned that this position of the epiglottis represented a clear physiological innovation in M.P.'s adductory mechanism that arose subsequent to the situation in 1979. Earlier it was indeed possible to see into the larynx during phonation and to observe a narrowing of the laryngeal sphincter during attempts at phonation. The sequence of events suggests that the rotation of the epiglottis is directly involved in some way with the improved phonatory mechanism that developed. Speculations as to what this role might be will be discussed at a later stage.

While the $\mathrm{X}$-ray data provided an invaluable perspective on these unusual physiological changes, they did not provide much useful information about the role of the vocal cords during phonation. At best they showed that the location of the cords changed during phonation and that they were probably elongated slightly as they shifted. Whether the cords actually vibrated and, if so, in what manner, had to be investigated by other means, namely, spectrographically and laryngographically.

The $L x$ and $F x$ tracings provide complementary information on the nature of the vibratory source. Briefly, they show that the vibrations are irregular in terms of their periodicity and waveform. This permits the inference that there is no fine control over the vibratory source so far as bulk and tension are concerned. The complex and variable waveform shapes present a unique picture with double peaking on either the closing or opening phase. No straightforward physiological interpretation of these complexities is possible because of M.P.'s abnormal anatomy. However, double peaking normally suggests that more than one structure may be involved in the vibratory source and that these are variably present in adduction and abduction. Typical candidates for this sort of complexity are the vocal cords together with the ventricular folds. In M.P.'s case this could be so, with the height discrepancies between the vocal cords adding yet another "level" to the structures involved in adduction.

Another structure that prima facie could be involved is the aryepiglottic adduction mechanism. Indeed, the $x$-ray data may be readily interpreted as showing that M.P. was simply using a well-known site for the development of a pseudo-glottis (Luchsinger and Arnold, 1965). However, apart from the unusually high position of the adduction, this possibility does not seem likely. First, if the vibratory source is located at this ary-epiglottic sphincter, it is difficult to account for the complete lack of visible vibration of either part. Neither the arytenoids nor the epiglottis could be seen to vibrate during either fiberoptic or cinefluorographic investigation. Second, the location of the electrodes was not sufficiently high on the neck to detect impedance changes at the level of M.P's ary- 
epiglottic sphincter. Third, the spectrographic evidence strongly suggests that M.P.'s vibratory source was unlikely to involve the arytenoid cartilages or epiglottis.

This evidence concerns the rich harmonic structure best seen on the acoustic sections in Figure 1. The large number of modes of vibration (i.e. harmonics) most strongly suggests that the vocal cords are dominantly involved in M.P.'s vibratory source. There are no other laryngeal structures capable of vibrating in that many modes. While this vibratory behaviour is less than optimal, involving aperiodicity and noise, it is, nevertheless, the best evidence we have that M.P.'s cords retain the potential for complex harmonic motion. There is no independent evidence that the false cords are involved and so the double peaking on the $\mathrm{Lx}$ waveform can be attributed to the uneven levels of the cords relative to one another and to the resulting asymmetrical adductory possibilities.

We now return to the role of the physiological changes seen in Figure 7. The question arises as to why these unusual supraglottal adjustments are necessary if M.P. is indeed using his true vocal cords for phonation. We suggest that they constitute M.P.'s adductory mechanism for the vocal cords in the absence of some of the parts of the normal mechanism. The fact that the changes are a pre-requisite for phonation, together with the observation that they directly affect the position of the cords on the xerograms suggests this is so. As to why the adduction mechanism should, in a sense, be so elaborate, we can only speculate that it represents a good example of transferred function in a larynx with extensive structural damage. M.P.'s control of the laryngeal sphincter is obviously not impaired and he has learnt to exercise a fine control over this highly efficient adductory mechanism in order to create conditions for vocal cord vibration.

The findings of the measures carried out on this case cannot be generalised to other cases of laryngeal trauma. However, some comments concerning the use of a battery of diagnostic measures are apposite. No one measure used in this study provides a complete diagnosis on its own. Rather, the value of each measure is highlighted, within the context of the battery as a whole. In evaluation of this subject, the objective analyses revealed acoustic displays of vocal parameters and the physiological mechanism responsible for phonation, and subjective analysis revealed the auditory quality of the phonation being produced by this mechanism.

When M.P. was referred for further voice therapy at the end of 1982 , it was clinically impossible to determine whether further therapy was indicated, and if so the nature of this therapy. It was only after a full battery of diagnostic measures was carried out, that it was possible to prognosticate. Results of the investigation indicated that M.P. was in fact using the optimal phonation possible with his damaged laryngeal mechanism; a final goal for therapy (Luchsinger and Arnold, 1965). Hence, no futher voice therapy was indicated.

In conclusion, a battery of diagnostic measures (both subjec- tive and objective measures) appears to be most valuable in the rehabilitative process of patients with vocal disorders.

A dearth of research on laryngeal trauma within the realm of speech pathology exists. It is hoped that this study will promote further interest in this area.

\section{ACKNOWLEDGEMENT}

Dr. M. Said's generous assistance with the cinefluorography is gratefully acknowledged.

\section{REFERENCES}

Abberton, E. Some Laryngographic Data for Korean Stops, J. Int. Phonetic Assoc., 2, 67-78, 1972.

Aronson, A.E. Clinical Voice Disorders, Brian C. Decker, New York, 1980.

Berry, R.J., Epstein, R., Fourcin, A.J., Freeman, M., MacCurtain, F. and Noscoe, N. An Objective Analysis of Voice Disorders: Part One, Br. J. Disord. Commun., 17, 67-76. 1982.

Boone, D.R. The Voice and Voice Therapy, Prentice-Hall Inc., Englewood Cliffs, New Jersey, 1977.

Fletcher, S.G., Shelton, R.L., Smith, C.C. and Bosma, J.F. Radiography in Speech Pathology, J. Speech. Hear. Dis., 25, 135-144, 1960.

Fourcin, A.J. Laryngoscopic Examination of Vocal Fold Vibration, in Ventilatory and Phonatory Control Systems, Wyke, B. (Ed.), Oxford University Press, London, 315-326. 1974.

Fry, D.B. The Physics of Speech, Cambridge University Press, 1979.

Kelman, A.W., Gordon, M.T., Morton, F.M. and Simpson, I.C. Comparison of Methods for Assessing Vocal Function, Folia Phoniatr., 33, 51-65, 1981.

Kerr, W.A. and Lanham, L.W. Anatomical and Spectrographic Analysis of the Voice in Disease: A report of Five Cases, Journal of the South African Speech and Hearing Association., 20, 81-107, 1973.

Luchsinger, R. and Arnold, G.E. Voice-Speech-Language, Wadsworth Publishing Co., Belmont, Ca., 1965.

Mitrinowicz-Modrezjewska, V:A. Posttraumatische Stiminstorungen und ihre Phoniatrische Behandlung, Folia Phoniatr., 15, 15-22, 1962.

Moll, K.L. Cinefluorographic Techniques in Speech Research, J. Speech Hear. Res., 227-241, 1960.

Rontal, C., Rontal, M. and Rolnick, M.I. Objective Evaluation of Voice Pathology using Voice Spectrography, Ann. Otol, Rhinol. and Laryngol., 84, 662-671, 1975.

Wechsler, E. Laryngographic Study of Voice Disorders, $\mathrm{Br}$. J. Disord. Commun., 12, 9-22, 1977.

Wendahl, R.W. Some Parameters of Auditory Roughness, Folia Phoniatr., 18, 26-32, 1966.

Wilson, D.K. Voice Problems of Children, The Williams and Wilkins Co., Baltimore, 1979. 


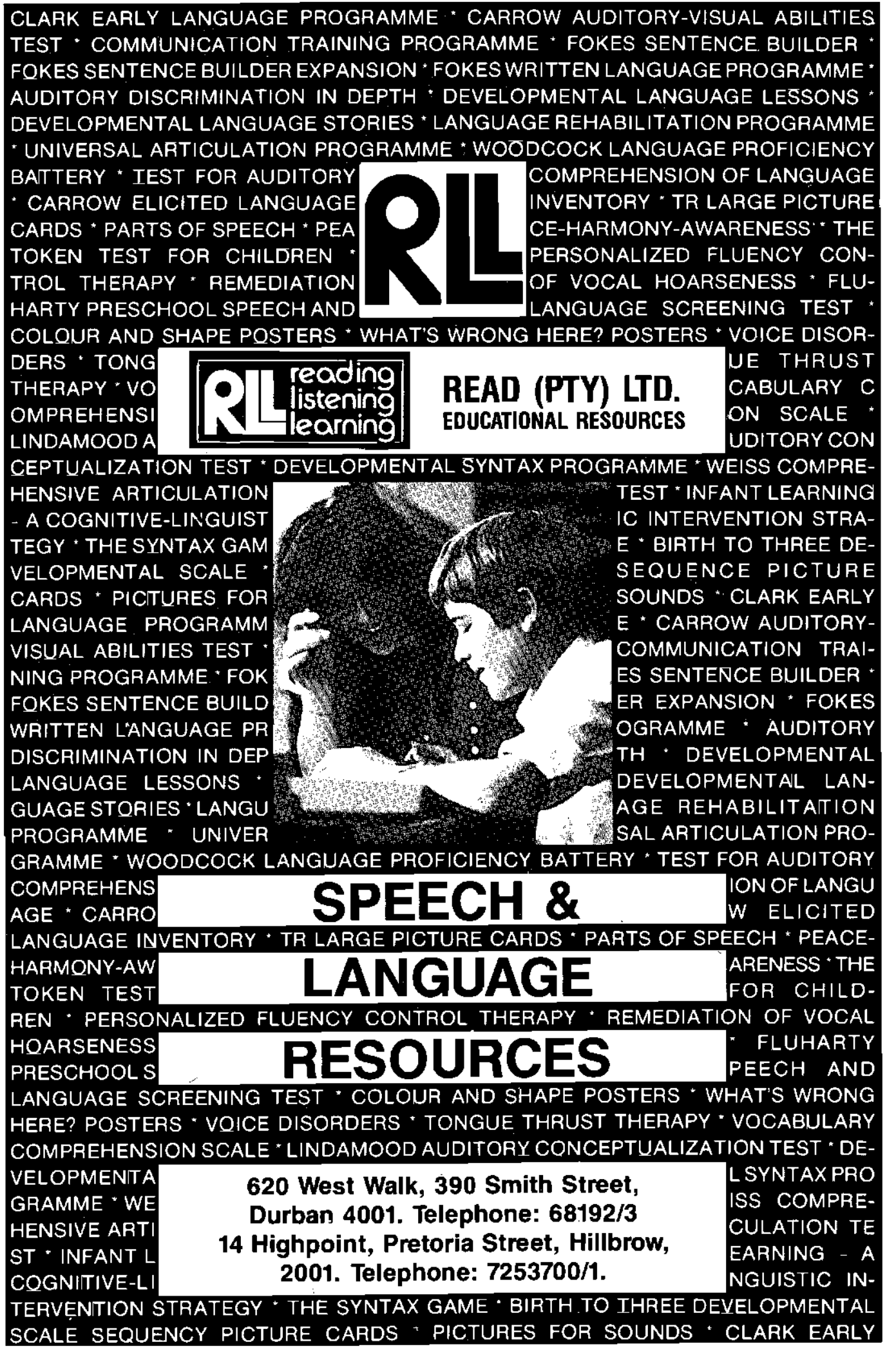

